\title{
Caracterização geomorfométrica e do uso do solo da Bacia Hidrográfica do Alto Meia Ponte, Goiás
}

\begin{abstract}
Pérola M. Calil ${ }^{1}$, Luiz F. C. de O liveira ${ }^{2}$, H uberto J. Kliemann ${ }^{3} \&$ Virlei A. de O liveira ${ }^{4}$
RESU M O

A caracterização geomorfométrica da utilização dos solos predominantes de uma bacia hidrográfica é importante para o entendimento da dinâmica dos processos que envolvem o balaço hidrológico e 0 transporte de sedimentos. O bjetivou-se, com este trabalho, a caracterização dos atributos morfométricos da Bacia Hidrográfica do Alto M eia Ponte, procurando associá-los com as classes de solos predominantes na área da bacia com a sua utilização e como analisar a semelhança geométrica entre as sub-bacias que a compõem. Em todas as etapas do trabalho se utilizaram de programas de SIG, carta topográfica do IBGE e imagens do satélite Landsat TM 5 e de levantamentos de campo. Obtidos os resultados verificouse que a Sub-Bacia Sb2, com predominância de Argissolos e Cambissolos, apresentou um padrão de drenagem mais ramificado porém, devido ao seu formato e à posição na paisagem, ela está mais propensa aos picos de cheia em resposta a chuvas de grandes intensidades e, portanto, mais vulnerável aos processos de erosão e transporte de sedimentos.
\end{abstract}

Palavras-chave: morfologia, semelhança geométrica, SIG

\section{Geomorphometric characterization and land use of the Upper M eia Ponte W atershed, Goiás}

\begin{abstract}
A B STRACT
The geomorphometric characterization and the land use of a watershed is important to understand the dynamics of the processes involving the hydrologic balance and sediment transport. In this context, the aim of this study was to characterize the morphometric attributes of the U pper M eia Ponte river watershed, trying to associate them with the predominant soil types and land use, and analyze the geometric similarity among the sub-basins that comprise it. At all stages of the study GIS programs was used, the IBGE topographic maps and Landsat TM 5 satellite images and field surveys. The results showed that the sub-basin Sb2, predominantly U Itisols and Inceptisol, has a more branched drainage pattern and due to its shape and position in the landscape, is more prone to spikes in full in response to large rainfall intensities and is, therefore, more vulnerable to erosion and sediment transport.
\end{abstract}

Key words: morphology, geometric similarity, GIS

\footnotetext{
${ }^{1}$ Secretaria de Agricultura, Pecuária e Irrigação de Goiás, Rua 256, o 52, Qd. 117, Setor Leste Universitário, CEP 74610-200, Goiânia, G0. Fone: (62) 3201-8905. E-mail: perolacalil@hotmail.com

2 DEG/U FLA, Departamento de Engenharia da UFLA, CEP 37200-000, Lavras, MG. Fone: (35)3829-1679. E-mail: coutinho@deg.ufla.br 3 EA/U FG, Escola de Agronomia e Engenharia de Alimentos da U FG, Campus Samambaia, Rod. Goiânia/N ova Veneza, km 0, CP 131, CEP 74690-900, Goiânia, GO. Fone: (62)3521-1530. E-mail: kliemann@agro.ufg.br

${ }^{4}$ Instituto Brasileiro de Geografia e Estatística, Av. 85, no 971, Setor Sul, CEP 74080-010, Goiânia, Go. Fone: (62)3225-4197. E-mail: virlei@ibge.gov.br
} 


\section{INTRODUÇÃO}

A compreensão relativa aos processos hidrológicos é fundamental em estudos ambientais, na gestão dos recursos hídricos e em projetos de obras hidráulicas (Zanetti et al., 2009). Neste contexto, a bacia hidrográfica tem-se revelado importante unidade espacial utilizada para gerenciar as atividades de uso e a conservação dos recursos naturais, sobremaneira nas situações atuais de grande pressão sobre o ambiente, em função do crescimento populacional e do desenvolvimento (Pissara et al., 2004).

Instituída por lei como unidade de planejamento, a bacia hidrográfica é uma ferramenta relevante de gestão ambiental, na qual se faz necessário o manejo adequado para que todos possam usufruir, de forma sustentável, deste ecossistema, respeitando a naturalidade dos recursos fornecidos ao homem e o melhor aproveitamento em benefício da sobrevivência dos espécimes e suas associações biológicas (Machado, 2003). Uma das principais causas da baixa disponibilidade hídrica se relaciona com as ações antrópicas, sem planejamento do uso e ocupação do solo nas bacias hidrográficas, responsáveis pela poluição da água (Lucas et al., 2010).

Torres et al. (2008) destacam a importância da bacia hidrográfica como unidade de planejamento visto que sua área de contribuição tem influência sobre a quantidade de água produzida como deflúvio e a forma e o relevo; no entanto, atua na taxa ou no regime dessa produção de água, tal como a taxa de sedimentação. Portanto, suas características governam, no seu interior, todo o fluxo superficial da água, sendo possível acompanhar as mudanças introduzidas pelo homem e as respectivas respostas da natureza (Rabelo et al., 2009). De acordo com Lima \& Zakia (2000) a bacia hidrográfica pode ser considerada um sistema geomorfológico aberto e, como tal, ela se encontra, mesmo quando não perturbada, em contínua flutuação, num estado de equilíbrio transacional ou dinâmico.

Segundo Souza \& Fernandes (2000) e Torres et al. (2010) a implantação de uma proposta de manejo integrado de uma bacia hidrográfica passa primeiramente pela elaboração de um diagnóstico básico, o qual levantam todos os problemas da bacia para análise dos conflitos e recomendação de soluções em todos os níveis. Apesar disto e em função das ações antrópicas, as bacias hidrográficas têm sofrido alterações na estrutura física dos canais, no aporte de sedimentos, no regime hidráulico e no fluxo de matéria e energia. Tais alterações e o padrão espacial do uso e cobertura do solo exercem efeitos relevantes sobre a produção e o transporte de sedimentos (Vanacker et al., 2005).

Para a análise de ecossistemas se destacam algumas características, como clima, geomorfologia, solo, vegetação, deflúvio e evapotranspiração, que contribuirão para a quantificação do processo hidrológico da bacia (Santos et al., 2007). Para Teodoro et al. (2007), as características físicas de uma bacia constituem elementos de grande importância para avaliação de seu comportamento hidrológico de vez que, ao se estabelecerem relações e comparações entre eles e dados hidrológicos conhecidos, pode-se determinar indiretamente os valores hidrológicos em locais em que faltem dados. Antoneli \& Thomaz (2007) ressaltam que a análise de aspectos relacionados à drenagem, relevo e geologia, pode levar à elucidação e compreensão de diversas questões associadas à dinâmica ambiental local.

No estudo da bacia hidrográfica é imprescindível considerar que se trata de uma unidade hidrogeomorfológica na qual os elementos de forma e os processos são estreitamente interdependentes, de tal maneira que qualquer mudança natural ou antrópica que venha a ocorrer em determinado ponto da bacia hidrográfica, produza automaticamente um ajustamento do sistema de drenagem (Barbosa \& Furrier, 2009).

Nos estudos de bacia hidrográfica a mensuração e a análise morfométrica da configuração da superfície terrestre são usadas nas estimativas das características da bacia hidrográfica, quanto à forma e às dimensões de sua paisagem (Sucupira et al., 2006). A interpretação geomorfológica traz informações relevantes para uma gestão eficaz de seus recursos naturais e para o entendimento de suas potencialidades e limitações quanto ao seu uso e ocupação (Pissara et al., 2004; Andrade et al., 2005). $\mathrm{O}$ estudo dos atributos morfométricos surge, portanto, como subsídio ao conhecimento da relação entre o relevo e a dinâmica hídrica da bacia (Alpino et al., 2007), constituindo-se em um dos primeiros e mais comuns procedimentos executados em análises hidrológicas ou ambientais e tem como objetivo elucidar as várias questões relacionadas ao o entendimento da dinâmica ambiental local e regional (Teodoro et al., 2007).

Quando aplicada em estudos de bacias hidrográficas a análise morfométrica possibilita a realização de uma análise quantitativa, através dos valores de um conjunto de atributos para se obter as características principais de uma área razão por que este fato se tornou uma importante ferramenta de análise em estudos morfológicos, para estabelecer unidades homogêneas nas áreas de estudo (Alves \& Castro, 2003; Barbosa \& Furrier, 2009). O uso do método morfométrico no estudo das bacias hidrográficas constitui-se num meio complementar para explicar as interações que ocorrem entre todos os elementos da paisagem, segundo Alcântara \& Amorim (2005), que abordam pedologia, relevo e rede hidrográfica, seus processos ambientais e descrevem a dinâmica das drenagens superficiais e as formas topográficas (Feltran Filho \& Lima, 2007). A rede de drenagem é constituída de um conjunto de canais de escoamento interligados que depende principalmente do relevo, da cobertura vegetal, do tipo de solo e da litologia e estrutura das rochas da bacia hidrográfica, sendo que a disposição dos rios, controlada em grande parte pela estrutura geológica, é definida pelo padrão de drenagem (Andrade et al., 2008; Oliveira et al., 2010). Tais indicadores revelam o formato da bacia, tipo de relevo, padrão de drenagem e a ordem dos canais, possibilidade de ocorrência de enchentes e erosões, recomendação de uso da área (Cardoso et al., 2006; Gobbi et al., 2008).

Em locais onde a infiltração é mais dificultada ocorre maior escoamento superficial, sendo possível também maior esculturação da rede hidrográfica, cuja consequência é uma densidade de drenagem mais alta. Demattê \& Demétrio (1996) verificaram estreita correlação entre a densidade de drenagem e determinados atributos morfológicos, químicos e mineralógicos, ligados à intensidade de intemperismo dos solos estudados. Dentre os elementos da paisagem utilizados para 
discriminar os solos e as áreas edáficas que incorporam outros atributos morfométricos está a densidade de drenagem (Silva \& Carvalho, 2002); portanto, a análise morfométrica da drenagem possibilita inferências sobre as características geológicas, geomorfológicas e pedológicas da bacia e pode servir também como parâmetro para o planejamento do uso e ocupação do solo, pois os atributos físicos podem estabelecer níveis de fragilidades relacionados às características físicas e ambientais da área, indicando as possibilidades e restrições ao uso atual e futuro do solo.

A subdivisão de uma bacia hidrográfica de maior ordem em microbacias permite a pontualização de problemas difusos, tornando mais fácil a identificação de focos de deterioração dos recursos naturais, dos processos de degradação ambiental instalados e do grau de comprometimento da produção existente; além disso, tem sido considerada área territorial ideal para o planejamento integrado dos recursos naturais (Alves Sobrinho et al., 2010; Pissarra et al., 2004). Primeiro, torna-se conveniente uma análise morfológica da bacia hidrográfica para que as formas possam ser separadas, descritas quantitativamente e comparadas de região para região (Cardoso et al., 2006). Segundo Porto \& Porto (2008), a questão da escala a ser utilizada depende do problema a ser solucionado e o tamanho ideal de bacia hidrográfica é aquele que incorpora toda a problemática de interesse. Teodoro et al. (2007) definem a microbacia como uma sub-bacia hidrográfica de área reduzida, não havendo consenso de qual seria a área máxima (máximo varia entre 10 a 20.000 ha ou 0,1 a $200 \mathrm{~km}^{2}$ ). Para os autores, são áreas formadas por canais de $1^{\mathrm{a}} \mathrm{e} 2^{\mathrm{a}}$ ordens e, em alguns casos, de $3^{\mathrm{a}}$ ordem, devendo ser definida como base na dinâmica dos processos hidrológicos, geomorfológicos e biológicos.

Segundo Santos et al. (2010), a modificação da paisagem vem sendo realizada, na maioria das vezes, irresponsavelmente, resultando na degradação dos mananciais, seja pela aceleração dos processos erosivos, alterações das disponibilidades hídricas ou mesmo pela contaminação por defensivos agrícolas e lançamento de efluentes urbanos e industriais. Portanto, fazse necessário, na caracterização física de uma bacia hidrográfica, o conhecimento das diferentes classes de solo e do seu uso e manejo que, dependendo de sua posição na paisagem, os tornam mais vulneráveis aos processos erosivos, proporcionado alterações no padrão de drenagem.

Em vista do exposto objetivou-se, com este trabalho, a caracterização dos atributos morfométricos da Bacia Hidrográfica do Alto Meia Ponte, procurando associá-los com as classes de solo predominantes na área da bacia e com sua utilização e, também, analisar a semelhança geométrica entre as sub-bacias que a compõem.

\section{MATERIAL E MÉTODOS}

O rio Meia Ponte nasce na Serra dos Brandões, entre os limites de Itauçu e Taquaral de Goiás, a 60 km de Goiânia, e percorre uma extensão de 471,6 km até desaguar no Rio Paranaíba; sua bacia hidrográfica abrange uma área de aproximadamente $12.180 \mathrm{~km}^{2}$, ou seja, cerca de $4 \%$ da área do estado de Goiás, sendo o principal manancial que abastece a cidade de Goiânia. A Bacia Hidrográfica do Alto Meia Ponte está compreendida entre as coordenadas de $16^{\circ} 06^{\prime}$ e $16^{\circ} 15^{\prime} \mathrm{S}$ e $49^{\circ} 30^{\prime}$ e $49^{\circ} 40 \mathrm{~W}$, na região central de Goiás, cuja área de drenagem é de $162,93 \mathrm{~km}^{2}$, incluindo os municípios de Itauçu e Inhumas (Figura 1). O clima predominante na região, segundo a classificação de Köppen, se enquadra no tipo Aw, característico dos climas úmidos tropicais, com duas estações bem definidas, Isto é, seca no inverno e úmida no verão.

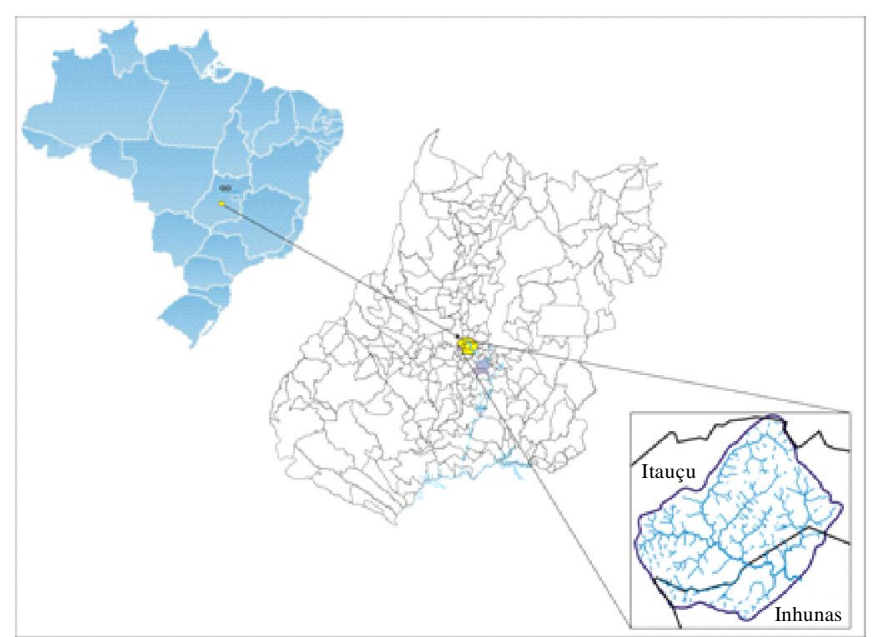

Figura 1. Bacia hidrográfica do Alto M eia Ponte, GO

A geologia da região é representada por rochas do complexo granulítico Anápolis-Itauçu, Associação Ortognáissica-Migmatítica e Suíte Gabro-Diorítica AnicunsSanta Bárbara, granitóides, além da geomorfologia pertencente ao Planalto Central Goiano com feições de relevo resultantes da exumação de estruturas dobradas no decorrer de vários ciclos tectônicos, com dois tipos particulares de relevo compostas pelas subunidades Planalto do Alto Tocantins-Paranaíba e Planalto Rebaixado de Goiânia, conforme descrito por Calil (2009).

Na etapa de elaboração da base cartográfica procedeu-se à conversão, digitalização e elaboração dos mapas, utilizandose os programas de Sistema de Informações Geográficas (SIG), Spring e ArcGis. Para a confecção do mapa preliminar da bacia utilizou-se a carta topográfica SE-22-X-A-III do IBGE, de onde se extraíram a rede de drenagem, o sistema viário e curvas de nível com a equidistância de $40 \mathrm{~m}$. A partir das curvas de nível gerou-se o modelo numérico do terreno, do qual se elaboraram os mapas de declividade, hipsometria e orientação de vertentes e, posteriormente, efetuou-se a interpretação de imagens do satélite Landsat TM5 nas bandas 2, 3, 4, 5 e 7, com passagem em maio de 2008. A composição colorida utilizada para os trabalhos de levantamento dos dados de campo foi a RGB-457 e, para o georreferenciamento das imagens foram usados os pontos de controle das drenagens contidas nas cartas topográficas.

Visando ao levantamento de uso e à ocupação dos solos utilizou-se a técnica de classificação supervisionada de imagens, descrita por Valle Júnior et al. (2010) e os pontos de controle foram tomados com o uso de Sistema de Posicionamento Global (GPS), escolhidos na imagem na fase preliminar e posteriormente verificados em campo. $\mathrm{O}$ 
levantamento de solos e sua classificação foram feitos de acordo com a metodologia preconizada e adotada pelo Centro Nacional de Pesquisa de Solos (CNPS) da Empresa Brasileira de Pesquisa Agropecuária (EMBRAPA, 2006). Foram coletados sete perfis completos e três pontos de amostras extras (horizontes A e B ou C), totalizando 33 amostras de forma que cada uma das principais classes de solo (dominante simples ou componente de associação) fosse representada por pelo menos um perfil completo ou um ponto de amostra extra.

A área de drenagem da Bacia Hidrográfica do Alto Meia Ponte foi subdividida em sete unidades menores para detalhamento das sub-bacias hidrográficas, assim denominadas: Sb1, Sb2, Sb3, Sb4, Sb5, Sb6 e Sb7. Para tal, as sub-bacias foram definidas pelos seus divisores internos, da mesma forma que o realizado para a bacia principal. As principais características físicas das sub-bacias hidrográficas obtidas por meio de uso de programa de SIG, foram: área, perímetro e comprimento axial da bacia, comprimento do rio principal, extensão total da rede de drenagem, altitudes máximas e mínimas e extensões das curvas de nível dentro da área da bacia.

Determinaram-se, com base nas características físicas das sub-bacias, os seguintes atributos morfométricos e fisiográficos: fator de forma (Kf); coeficiente de compacidade (Kc); índice de circularidade (Ic); frequência da rede de drenagem (Dr); sinuosidade do rio principal (Sin); coeficiente de manutenção $(\mathrm{Cm})$; densidade de drenagem (Dd); razão de textura $(\mathrm{T})$; declividade média da bacia $(\mathrm{H})$; amplitude altimétrica (Hm); relação do relevo (Rr); índice de rugosidade (Ir) e coeficiente rugosidade (CR), conforme descrito por Calil (2009) e Politano \& Pissarra (2003), definidos na Tabela 1.

Tabela 1. Atributos morfométricos e fisiográficos empregados na caracterização da Bacia Hidrográfica do Alto Meia Ponte

\begin{tabular}{lc}
\hline Atributo & Definição \\
Fator de forma & $\mathrm{Kf}=\frac{\mathrm{Lm}}{\mathrm{L}^{2}}$ \\
Coeficiente de compacidade & $\mathrm{Kc}=2,08 \frac{\mathrm{P}}{\sqrt{\mathrm{A}}}$ \\
Índice de circularidade & $\mathrm{Ic}=\mathrm{Kc}^{-2}$ \\
Frequência da rede de drenagem & $\mathrm{Dr}=\frac{\mathrm{N}}{\mathrm{A}}$ \\
Sinuosidade do rio principal & $\mathrm{Sin}=\frac{\mathrm{Lt}}{\mathrm{L}}$ \\
Densidade de drenagem & $\mathrm{Dd}=\frac{\sum \mathrm{L}}{\mathrm{A}}$ \\
Coeficiente de manutenção & $\mathrm{Cm}=\frac{1000}{\mathrm{Dd}}$ \\
Razão de textura & $\mathrm{T}=\frac{\mathrm{Nt}}{\mathrm{P}}$ \\
Declividade média da bacia & $\mathrm{H}=0\left(\sum \mathrm{Ln} \frac{\Delta \mathrm{h}}{\mathrm{A}}\right)$ \\
Amplitude altimétrica & $\mathrm{Hm}=\mathrm{Hmáx}-\mathrm{Hm}$ ín \\
Relação do relevo & $\mathrm{Rr}=\frac{\mathrm{Hm}}{\mathrm{Lt}}$ \\
Índice de rugosidade & $\mathrm{Ir}=\mathrm{Hm} . \mathrm{Dd}$ \\
Coeficiente rugosidade & $\mathrm{CR}=\mathrm{Dd} . \mathrm{H}$
\end{tabular}

L - comprimento axial da bacia $(\mathrm{km}) ; \mathrm{Lm}$ - largura média da bacia $(\mathrm{km}) ; \mathrm{P}$ - perímetro bacia $(\mathrm{km})$; $\mathrm{A}$ - área da bacia $\left(\mathrm{km}^{2}\right) ; \mathrm{N}$ - número total de cursos d'água da bacia; Lt - comprimento do rio principal $(\mathrm{km})$; "L - extensão total dos cursos de água $(\mathrm{km})$; Nt - relação entre o número total de segmentos de rios de $1 \underline{a}$ ordem da bacia e seu respectivo perímetro; $h$ - equidistância entre duas curvas de nível subseqüentes (km); "Ln - o comprimento das curvas de nível compreendidas na bacia $(\mathrm{km})$; Hmáx - Hmín - diferença altimétrica entre a foz e a maior altitude situada num determinado ponto da área da bacia
$\mathrm{Na}$ análise da semelhança geométrica entre as sub-bacias empregou-se o método proposto por Strahler modificado por França (1968), que permite comparar as semelhanças entre as sub-bacias, pelas médias ponderadas de seus parâmetros dimensionais. Os atributos utilizados neste método são: comprimento axial $\left(\mathrm{L}_{\mathrm{a}}\right)$ e maior largura das bacias (L); comprimento do rio principal $\left(\mathrm{L}_{\mathrm{p}}\right)$, comprimento total da rede $\left(\mathrm{L}_{\mathrm{r}}\right)$, perímetro $(\mathrm{P})$ e área $(\mathrm{A})$ das bacias (Eq. 1), em que os numeradores das relações lineares se referem aos atributos de uma bacia e os denominadores a uma segunda bacia.

$$
\mathrm{R}_{\mathrm{m}}=\frac{1}{5}\left[\frac{\mathrm{L}_{\mathrm{a}}}{\mathrm{L}_{\mathrm{a}}^{\prime}}+\frac{\mathrm{L}}{\mathrm{L}^{\prime}}+\frac{\mathrm{L}_{\mathrm{p}}}{\mathrm{L}_{\mathrm{p}}^{\prime}}+\frac{\mathrm{L}_{\mathrm{r}}}{\mathrm{L}_{\mathrm{r}}^{\prime}}+\frac{\mathrm{P}}{\mathrm{P}^{\prime}}\right]
$$

O teste de semelhança geométrica consiste na comparação entre o quadrado da média das razões entre os parâmetros lineares $\left(\mathrm{R}_{\mathrm{m}}\right)$ e a razão das áreas (A/A'), sendo que, quanto mais próximo $\mathrm{A} / \mathrm{A}^{\prime}$ for de $\mathrm{R}_{\mathrm{m}}{ }^{2}$ poder-se-á considerar a semelhança geométrica entre as sub-bacias analisadas.

Também se procurou, neste trabalho, associar as classes de solo com o padrão da rede drenagem nas sub-bacias hidrográficas e o potencial uso do solo a partir do coeficiente de rugosidade, analisando a vulnerabilidade do uso atual com relação aos possíveis impactos ambientais.

\section{RESULTADOS E DISCUSSÃO}

A Figura 2 apresenta os mapas dos solos predominantes na Bacia Hidrográfica do Alto Meia Ponte, os usos e os tipos de cobertura vegetal observados na imagem do Landsat TM5 e validados no campo. Verifica-se predomínio do Argissolo Vermelho eutrófico típico (PVe) totalizando 34,98\% da área total da bacia, seguido do Argissolo Vermelho-Amarelo eutrófico típico (PVAe), Cambissolo Háplico eutrófico típico (CXbe) e do Latossolo Vermelho distrófico típico (LVd) com 18,48; 17,14 e $15,26 \%$, respectivamente (Figura 2A e Tabela 2). Associado a essas classes de solo verifica-se predomínio de pastagens e de remanescente de vegetação nativa, representando 55,0 e $17,39 \%$ da área total da bacia hidrográfica, respectivamente (Tabela 3).

A atividade agricultura representa $10,67 \%$ da área total da bacia desenvolvida nos Latossolos e Argissolos, solos considerados aptos a este tipo de atividade, em virtude de apresentarem vulnerabilidade a erosão hídrica de baixa a moderada. Pela ocupação dos solos da Bacia Hidrográfica do Alto Meia Ponte, percebe-se uma preocupação conservacionista por parte dos agricultores da manutenção de áreas de vegetação nativa associada aos Cambissolos, classe de solo com maior grau de vulnerabilidade ao processo erosivo em virtude da baixa capacidade de infiltração de água, profundidade do perfil e posição na paisagem. Por outro lado, verificou-se um descaso com as áreas de preservação permanente nas nascentes e faixas de domínio dos cursos de água que compõem a rede de drenagem da bacia, representando 8,34\% da área total da bacia hidrográfica (Figura 2B e Tabela 3). 
A.
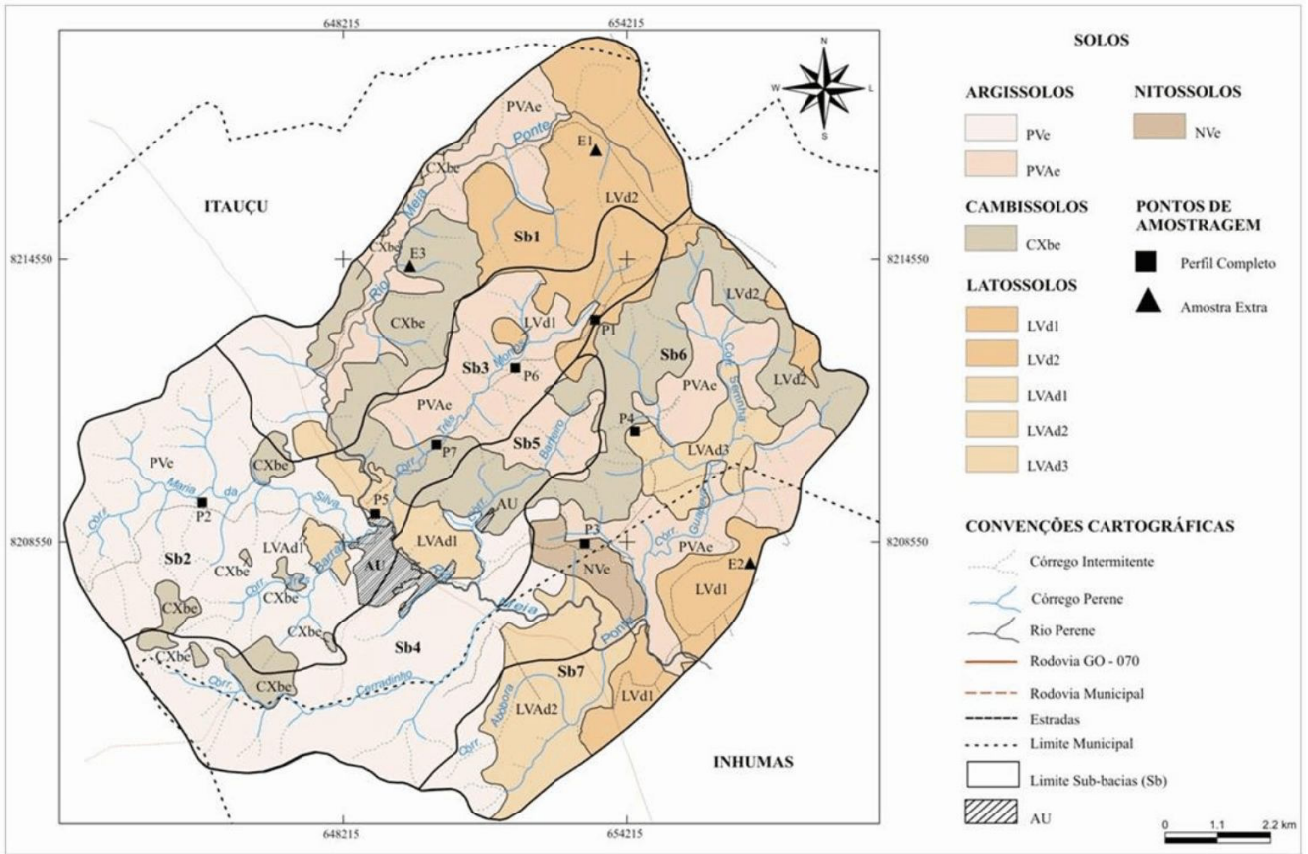

B.

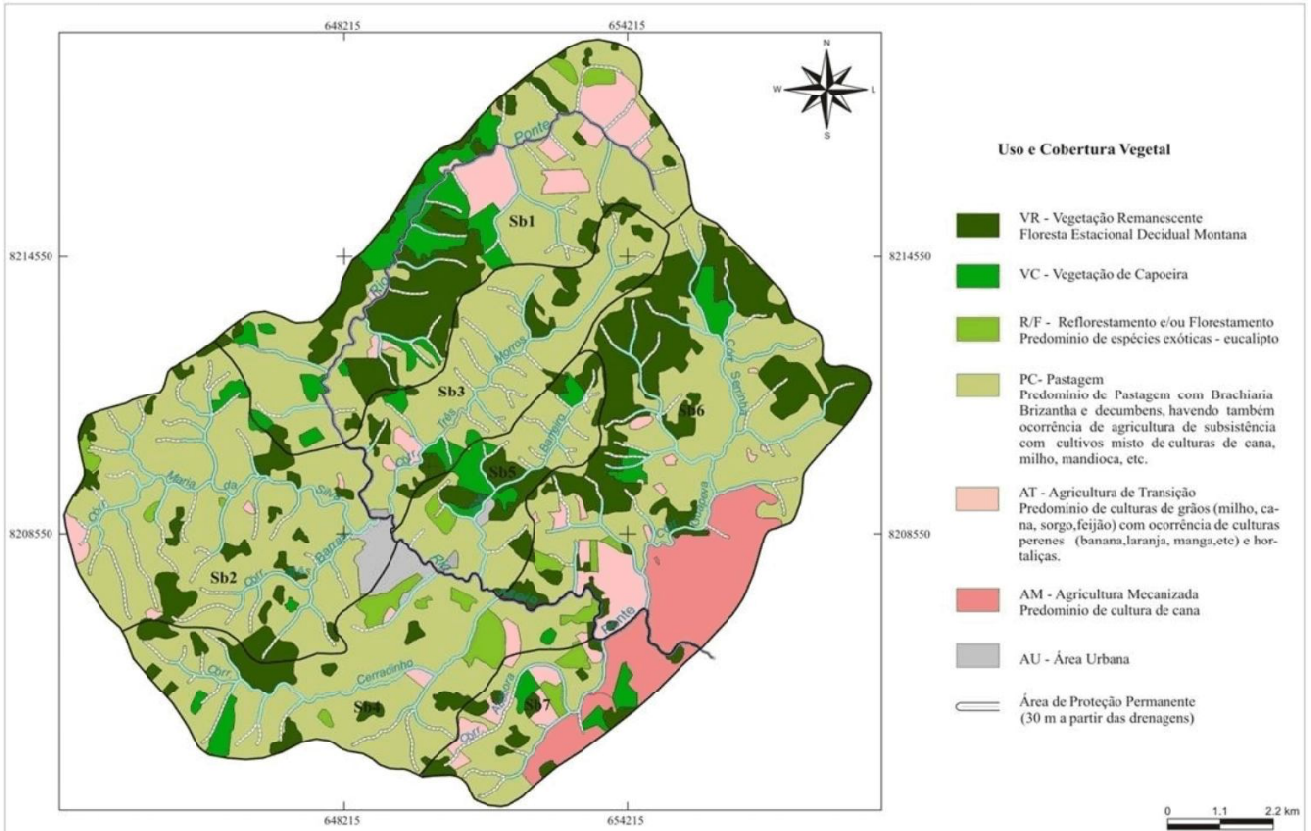

Figura 2. Mapas de solos (A) e de uso e cobertura vegetal (B) da Bacia Hidrográfica do Alto M eia Ponte, Goiás

Tabela 2. U nidades de solos predominantes nas Sub-Bacias H idrográficas do Alto M eia Ponte, G oiás

\begin{tabular}{cccccccccc}
\hline \multirow{2}{*}{ Sub-bacias } & \multicolumn{10}{c}{ Unidades de solos (\%) } \\
\cline { 2 - 10 } & PVe & PVAe & CXbe & LVd1 & LVd2 & LVAd1 & LVAd2 & LVAd3 & NVe \\
Sb1 & 2,49 & 5,12 & 4,67 & - & 7,86 & 0,33 & - & - \\
Sb2 & 15,87 & - & 1,37 & - & - & 0,93 & - & - \\
Sb3 & 0,02 & 5,44 & 1,22 & 0,22 & 2,35 & 0,46 & - & - \\
Sb4 & 11,78 & - & 0,79 & - & - & - & 1,17 & - \\
Sb5 & 2,74 & - & 2,16 & - & 0,10 & 1,17 & - & - \\
Sb6 & 0,83 & 7,80 & 6,94 & 2,32 & 1,04 & - & 0,68 & 2,70 & 1,48 \\
Sb7 & 1,24 & 0,12 & - & 1,36 & - & - & 3,88 & - \\
\hline Total & 34,98 & 18,48 & 17,14 & 3,91 & 11,35 & 2,89 & 5,73 & 2,70 & - \\
\hline
\end{tabular}

PVe - Argissolo Vermelho eutrófico típico, PVAe - Argissolo Vermelho-Amarelo eutrófico típico, CXbe - Cambissolo Háplico eutrófico típico, LVd1 - Latossolo Vermelho distrófico típico, LVd2 - Latossolo Vermelho distrófico típico associado ao PVe, LVAd1 - Latossolo Vermelho-Amarelo distrófico típico, LVAd2 - Latossolo Vermelho-Amarelo distrófico típico associado ao PVe, LVAd3 - Latossolo Vermelho-Amarelo distrófico típico associado ao CXbe e NVe - Nitossolo Vermelho eutrófico típico 
Tabela 3. U sos e tipos de cobertura vegetal ocorrentes na área, associados às classes de solos predominantes da Bacia Hidrográfica do Alto M eia Ponte, Goiás

\begin{tabular}{llc}
\hline Tipos de uso e cobertura vegetal & $\begin{array}{l}\text { Classes } \\
\text { de solos }\end{array}$ & Área $\mathbf{( k m}^{2}$ ) \\
Pastagem (PG) & $\begin{array}{c}\text { Argissolos } \\
\text { Latossolos }\end{array}$ & 89,61 \\
Vegetação remanescente (VR) & $\begin{array}{c}\text { Cambissolos } \\
\text { Latossolos }\end{array}$ & 28,33 \\
Reflorestamento/florestamento (R/F) & $\begin{array}{c}\text { Argissolos } \\
\text { Argissolos }\end{array}$ & 3,64 \\
Vegetação de capoeira (VC) & $\begin{array}{c}\text { Cambissolos } \\
\text { Latossolos }\end{array}$ & 8,46 \\
Agricultura tardicional (AT) & Argissolos & 8,46 \\
Agricultura mecanizada (AM) & Latossolos & 8,93 \\
Mata galeria (MG) & - & 13,60 \\
Área urbana (AU) & Argissolos & 1,91 \\
\hline
\end{tabular}

A Tabela 4 apresenta as características fisiográficas e morfométricas das Sub-Bacias Hidrográficas do Alto Meia Ponte. Observa-se, na referida tabela, que as áreas das subbacias variaram entre 10,26 a $38,85 \mathrm{~km}^{2}$, sendo a de menor área a Sub-Bacia Sb5 e a maior a Sb6. Devido à regularidade no formato das sub-bacias, seu perímetro acompanhou a tendência das áreas, sendo as de menor e maior perímetro as sub-bacias $\mathrm{Sb} 5$ e Sb6, respectivamente. Com relação aos comprimentos do rio principal e axial das sub-bacias estudadas, há tendência de que essas dimensões sejam maiores quanto maiores forem as dimensões das sub-bacias. Verifica-se que, embora a área da Sub-Bacia Sb1 seja menor do que a Sb6, o comprimento do rio principal foi maior na primeira e, devido à pequena diferença entre os comprimentos axiais das mesmas, o rio principal da Sub-Bacia Sb1 é mais sinuoso, o que aumentará o tempo de concentração do escoamento em sua calha, proporcionando cheias nas partes mais baixas da bacia, atenuando a vazão de pico no exutório.
A rede de drenagem Bacia Hidrográfica do Alto Meia Ponte, ordenada, segundo a metodologia de Strahler, como de $5^{\text {a }}$ ordem com o padrão dendrítico (Figura 1), não possui uma orientação preferencial, exceto quando são observados os canais de $1^{\mathrm{a}} \mathrm{e}$ $2^{\mathrm{a}}$ ordens, o que sugere um padrão subparalelo, coincidente com as direções dos lineamentos estruturais geológicos. Apesar do padrão de drenagem não ser diagnóstico, verificouse que suas características possuem diferenciação significativa na densidade de drenagem em relação às classes de solo e aos tipos de relevo, principalmente nas classes de solo verificadas nas áreas menos declivosas e com tendência de infiltração maior de água, como os Latossolos, para os quais se verificou menor dissecação do relevo. Para as classes de solo presentes no relevo de ondulado a escarpado que o escoamento superficial é maior em detrimento da infiltração de água no solo, como os Argissolos e Cambissolos, verifica-se um padrão de drenagem mais ramificado, com a rede de drenagem de ordem mais elevada, comportamento bem evidenciado nas Sub-Bacias $\mathrm{Sb} 1, \mathrm{Sb} 2, \mathrm{Sb} 3$ e Sb6. Avaliando a rede de drenagem em relação às dimensões das sub-bacias, nota-se tendência de nas maiores sub-bacias haver maior extensão dos cursos de água, sendo as Sub-Bacias Sb1, Sb2 e Sb6 as que apresentaram a maior quantidade de cursos de água e comprimento total da rede de drenagem. A mesma tendência foi verificada no total de tributários de $1^{\mathrm{a}}$ ordem e pode ser atribuída à área de captação das chuvas que, associada às classes de solo e ao relevo, permite que o escoamento superficial gerado escave a rede de drenagem nos pontos de menor resistência à ação cisalhante do escoamento sobre o solo.

Pela variação das altitudes nas sub-bacias pode-se verificar, ainda, que a $\mathrm{Sb} 7$ apresenta menor amplitude, refletindo em menores velocidades médias do escoamento superficial sobre os terrenos e que, associada à menor área de captação de chuva, proporciona uma rede de drenagem menos ramificada, de menor

Tabela 4. Características fisiográficas e morfométricas das Sub-Bacias Hidrográficas do Alto M eia Ponte, G oiás

\begin{tabular}{|c|c|c|c|c|c|c|c|}
\hline Sub-bacia & Sbl & Sb2 & Sb3 & Sb4 & Sb5 & Sb6 & Sb7 \\
\hline Área da sub-bacia $\left(\mathrm{km}^{2}\right)$ & 33,4 & 30,6 & 15,9 & 23,2 & 10,3 & 38,9 & 10,8 \\
\hline Perímetro $(\mathrm{km})$ & 30,8 & 24,2 & 22,5 & 28,0 & 16,1 & 31,3 & 16,2 \\
\hline Comprimento do rio principal (km) & 13,9 & 8,9 & 9,1 & 9,6 & 5,9 & 10,6 & 4,8 \\
\hline Comprimento axial $(\mathrm{km})$ & 8,6 & 6,5 & 8,0 & 8,0 & 5,5 & 8,7 & 4,4 \\
\hline Extensão dos cursos de água (km) & 44,1 & 50,7 & 24,6 & 28,0 & 16,7 & 50,1 & 13,5 \\
\hline Extensão das curvas de nível (km) & 114,3 & 122,3 & 54,0 & 85,0 & 42,8 & 142,0 & 22,6 \\
\hline Total dos cursos de água & 34,0 & 36,0 & 20,0 & 17,0 & 20,0 & 33,0 & 8,0 \\
\hline Total de cursos de 1 a ordem & 29,0 & 31,0 & 17,0 & 14,0 & 16,0 & 26,0 & 6,0 \\
\hline Altitude máxima & 1040,0 & 1000,0 & 1040,0 & 1000,0 & 960,0 & 1040,0 & 920,0 \\
\hline Altitude mínima & 840,0 & 840,0 & 840,0 & 800,0 & 800,0 & 800,0 & 800,0 \\
\hline Hierarquia dos canais & $3 \underline{a}$ & $4^{a}$ & 3 & $3 \underline{a}$ & 3 & $4 \underline{a}$ & $2^{\underline{a}}$ \\
\hline Coeficiente de compacidade & 1,5 & 1,2 & 1,6 & 1,6 & 1,4 & 1,4 & 1,4 \\
\hline Fator de forma & 0,5 & 0,7 & 0,3 & 0,4 & 0,4 & 0,5 & 0,6 \\
\hline Índice de circularidade & 0,5 & 0,7 & 0,4 & 0,4 & 0,5 & 0,5 & 0,5 \\
\hline Frequência da rede de drenagem & 1,0 & 1,2 & 1,3 & 0,7 & 2,0 & 0,9 & 0,7 \\
\hline Coeficiente de manutenção $\left(\mathrm{m}^{2} \mathrm{~m}^{-1}\right)$ & 756,8 & 603,1 & 648,6 & 827,0 & 614,7 & 775,8 & 801,5 \\
\hline Sinuosidade do rio principal & 1,6 & 1,4 & 1,1 & 1,2 & 1,1 & 1,2 & 1,1 \\
\hline Densidade de drenagem $\left(\mathrm{km} \mathrm{km}^{-2}\right)$ & 1,3 & 1,7 & 1,5 & 1,2 & 1,6 & 1,3 & 1,3 \\
\hline Razão de textura & 0,9 & 1,3 & 0,8 & 0,5 & 1,0 & 0,8 & 0,4 \\
\hline Declividade média (\%) & 13,7 & 16,0 & 13,6 & 14,7 & 16,7 & 14,6 & 8,4 \\
\hline Amplitude altimétrica (m) & 200,0 & 160,0 & 200,0 & 200,0 & 160,0 & 240,0 & 120,0 \\
\hline Relação do relevo $\left(\mathrm{m} \mathrm{km}^{-1}\right)$ & 14,4 & 17,9 & 21,9 & 20,9 & 27,3 & 22,6 & 25,0 \\
\hline Índice de rugosidade & 264,3 & 265,3 & 308,4 & 241,8 & 260,3 & 309,4 & 149,7 \\
\hline Coeficiente de rugosidade & 18,1 & 26,5 & 20,9 & 17,7 & 27,2 & 18,8 & 10,5 \\
\hline
\end{tabular}


ordem. O contrário se verifica nas Sub-Bacias Sb2 e Sb6, que apresentam grandes áreas de captação e diferença de nível, proporcionando uma rede de drenagem de maior comprimento total e mais ramificada ( $4^{\mathrm{a}}$ ordem).

Pelos resultados obtidos com relação às características morfométricas tem-se que, com exceção das Sub-Bacias Sb2 e $\mathrm{Sb7}$, as demais possuem forma alongada, aproximando-se do retângulo com $\mathrm{Kc}>1,25, \mathrm{Kf}<0,5$ e Ic < 0,51 (Tonello et al., 2006; Périco et al., 2011). A Sub-Bacia Sb7 aproxima-se da forma quadrada e a Sb2 da forma circular, apresentando maior propensão à ocorrência de cheias em resposta às chuvas de alta intensidade nas quais o tempo de concentração provavelmente será inferior ao das demais, proporcionando maior vazão de pico no exutório. Por outro lado, as sub-bacias com formato retangular podem apresentar picos de cheia quando da ocorrência de chuvas frontais que apresentam as características de serem de baixa intensidade, longa duração e cobrir grandes áreas. Neste caso, como toda a área da subbacia estará contribuindo para o escoamento superficial e devido à longa duração das chuvas, há tendência de aumento do escoamento superficial.

Os valores de Dd encontrados nas sete sub-bacias ficaram abaixo de 5,0 $\mathrm{km} \mathrm{km}^{-2}$, o que as classificam como de baixa densidade de drenagem (Tonello et al., 2006; Périco et al., 2011). Embora os valores de Dd sejam considerados baixos, o maior valor foi observado na Sub-Bacia Sb2, na qual há predomínio de Argissolo Vermelho eutrófico típico. Esta classe de solo apresenta baixas taxas de infiltração de água e, juntamente com sua posição na paisagem, favorece o surgimento do escoamento superficial, condicionando o desenvolvimento da rede de drenagem. Esta análise, associada à da forma da bacia, sinaliza para a necessidade de práticas conservacionistas intensas, a fim de se evitar grandes picos de cheia e transporte de sedimentos pelos processos erosivos.

Com relação aos índices T e Dr, verificou-se tendência dos maiores valores estarem associados às sub-bacias maiores e com maior rede de drenagem, sendo novamente a $\mathrm{Sb} 2$ a de maior número de tributários de $1^{\mathrm{a}}$ ordem e de maior comprimento total dos cursos de água que compõem a rede de drenagem. Comparando os valores de Dd com os de T e Dr, verifica-se que esses índices tendem a aumentar sempre que o relevo se torna mais movimentado. Dessas observações pode-se inferir que nas Sub-Bacias Sb2, Sb5 e Sb3 os valores desses coeficientes são altos, em virtude do relevo mais dissecado, com topos convexos. Nessas sub-bacias os Argissolos e os Cambissolos são mais representativos e resultam em maior escoamento superficial contribuindo, portanto, para o aprofundamento dos vales e maior dissecação nas vertentes.
Os menores valores de $\mathrm{T}$ e $\mathrm{Dr}$ foram observados nas SubBacias Sb4 e Sb7, com predomínio de Latossolos, ou associação de Latossolos com Argissolos com relevo suave ondulado a ondulado com topos convexos e tabulares; os valores intermediários nas Sb1 e Sb6 se devem, provavelmente, às maiores taxas de infiltração desses solos em relação aos demais e, consequentemente, à redução da formação de canais de escoamento e da Dd, T e Dr.

Os coeficientes de manutenção $(\mathrm{Cm})$ que representam a área mínima necessária para a manutenção de um metro de canal de escoamento, aumentam na medida em que o relevo se torna mais plano, mostrando que nas sub-bacias nas quais há predomínio dos Argissolos e Cambissolos, os índices são menores que nos Latossolos. Este comportamento pode ser explicado quando da ocorrência de chuvas de grandes intensidades nas áreas planas, quando o escoamento superficial tende a se concentrar, formando fluxos preferenciais e gerando, desta forma, os canais que compõem a rede de drenagem. No relevo mais acidentado o escoamento superficial tende a seguir a declividade natural do terreno escavando o solo nos pontos de menor resistência ao cisalhamento, proporcionado uma concentração maior de canais naturais e, por sua vez, a maior densidade de drenagem.

Com exceção da Sub-Bacia Sb1, os índices de sinuosidade do rio principal (Sin) foram inferiores a 1,5 , evidenciando tendência para canais retilíneos, o que está de acordo com a análise feita anteriormente acerca dos comprimentos do rio principal e axial na área da Sub-Bacia Sb1 (Tonello et al., 2006; Périco et al., 2011); portanto, o curso principal da Sub-Bacia Sb1 pode ser classificado como sinuoso, o que tende a aumentar o tempo de concentração em sua calha, reduzindo o pico de cheia na bacia.

Pela distribuição das classes de declividade na Bacia e SubBacias do Alto Meia Ponte, observa-se predominância de declives entre as classes plana a ondulada, com declividade média foi inferior a 17\% (Tabela 2), representando 87,22\% da área total da bacia, associadas aos Latossolos e Argissolos ocupados com pastagens, agricultura e reflorestamento (Tabela 5 e Figura 3). Para as classes com declividades de forte ondulado a escarpado, há predomínio dos Cambissolos ocupados com vegetação natural, o que reforça a preocupação conservacionista dos agricultores locais devido à alta vulnerabilidade dessas áreas à erosão hídrica. Observa-se, na Tabela 4, que existe uma distribuição proporcional das classes de declividade nas sub-bacias seguindo a mesma tendência da bacia hidrográfica, como um todo, com declives mais acentuados na região das nascentes, tornando-se mais suaves na proximidade da foz (Figura 3A).

Tabela 5. Classes de declividade das Sub-Bacias H idrográficas do Alto M eia Ponte, G oiás

\begin{tabular}{|c|c|c|c|c|c|c|c|c|c|}
\hline \multirow{2}{*}{$\begin{array}{c}\text { Declividades } \\
(\%)\end{array}$} & \multirow{2}{*}{ Relevo } & \multicolumn{7}{|c|}{ Porcentagem da área das sub-bacias (sb) } & \multirow{2}{*}{ Total } \\
\hline & & Sb1 & Sb2 & Sb3 & Sb4 & Sb5 & Sb6 & Sb7 & \\
\hline $0-3$ & Plano & 7,11 & 5,62 & 3,51 & 4,32 & 1,82 & 7,83 & 3,02 & 33,22 \\
\hline $3-8$ & Suave Ondulado & 3,13 & 3,21 & 1,85 & 2,63 & 0,95 & 4,16 & 2,08 & 18,00 \\
\hline $8-20$ & Ondulado & 7,70 & 7,69 & 3,01 & 6,11 & 2,32 & 7,70 & 1,46 & 36,00 \\
\hline $20-45$ & Forte Ondulado & 2,39 & 2,18 & 1,35 & 1,10 & 1,14 & 3,97 & 0,06 & 12,20 \\
\hline $45-75$ & Montanhoso & 0,14 & 0,06 & 0,06 & 0,02 & 0,07 & 0,18 & 0,01 & 0,54 \\
\hline$>75$ & Escarpado & 0,02 & 0,00 & 0,00 & 0,00 & 0,00 & 0,02 & 0,00 & 0,04 \\
\hline
\end{tabular}


A.

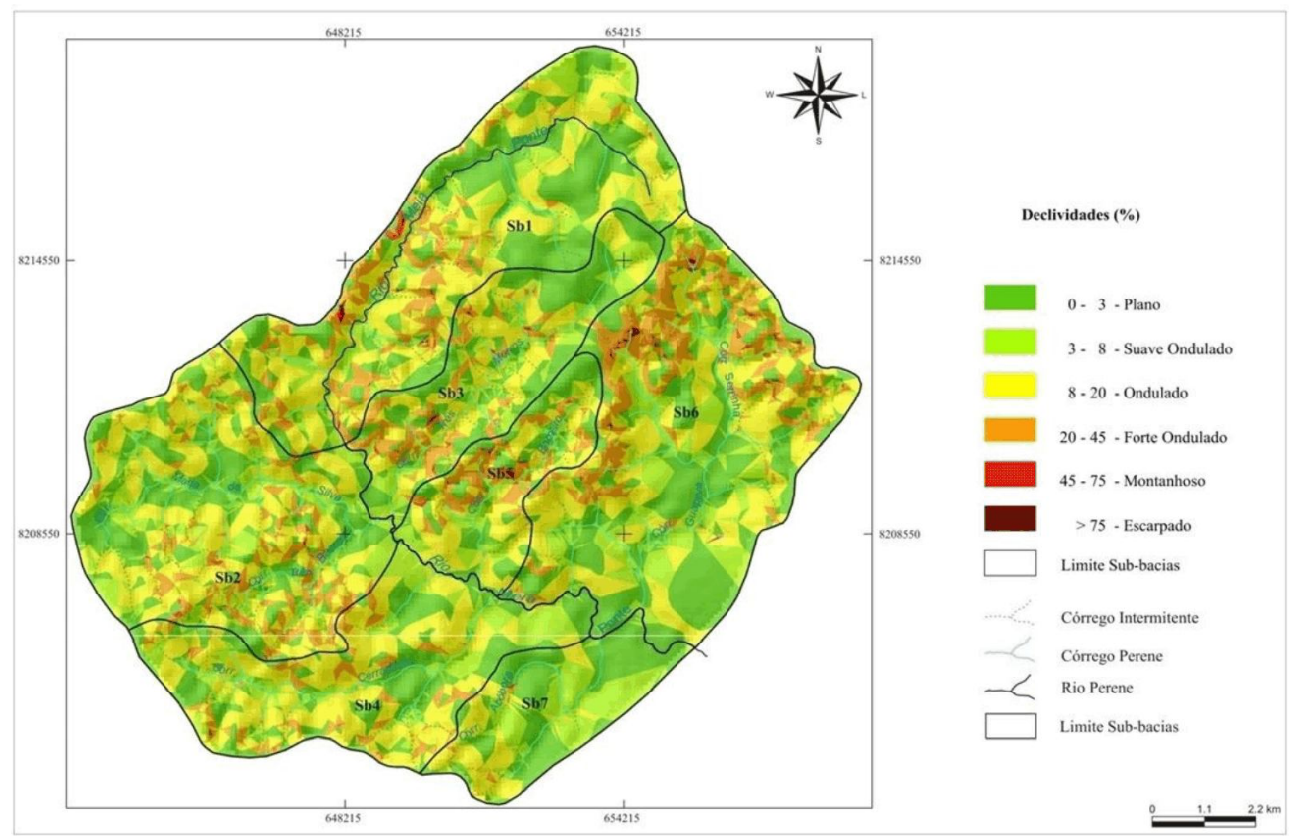

B.

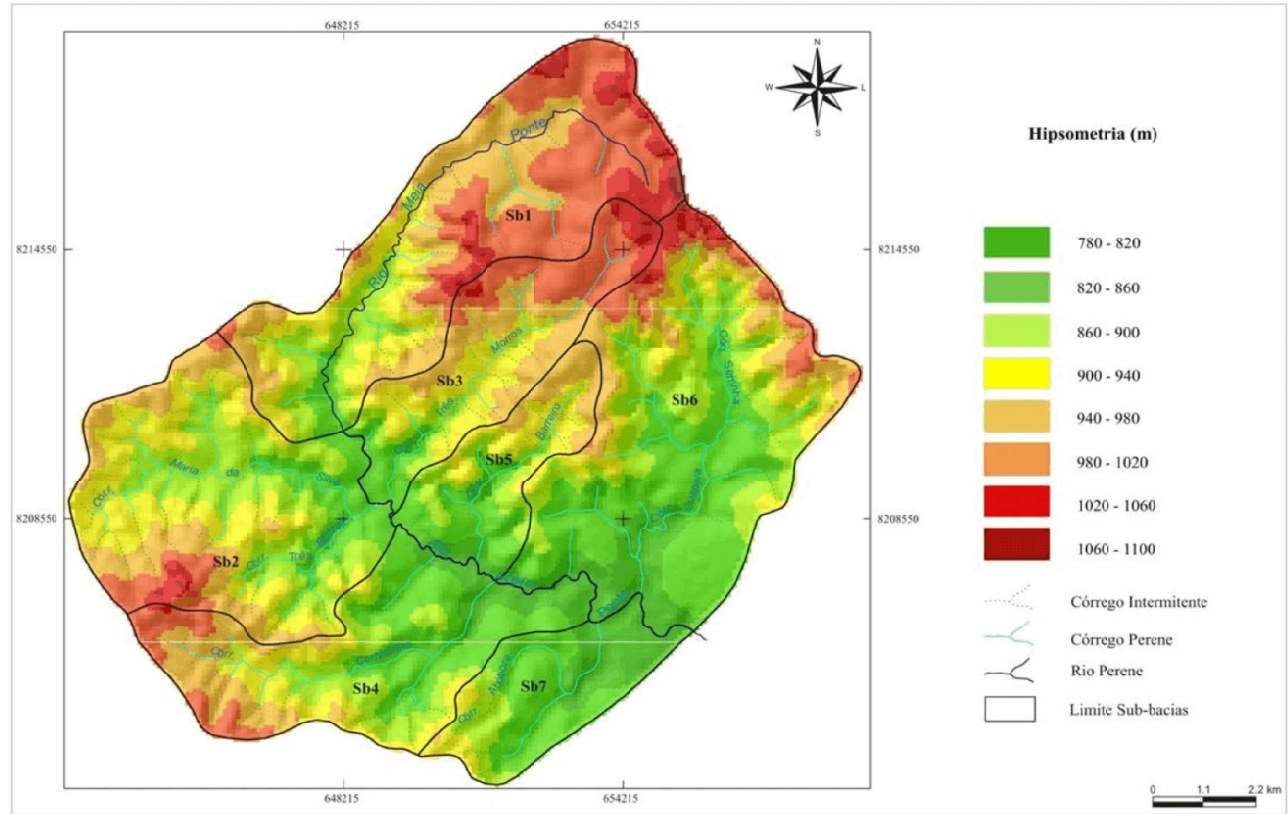

Figura 3. Classes de declividade e hipsometria da Bacia H idrográfica do Alto M eia Ponte, G oiás

A Sub-Bacia $\mathrm{Sb} 7$ foi a que apresentou menor declividade média sendo classificada como de relevo suave ondulado, na qual se observa um desenvolvimento menor do relevo, associado a um comprimento menor das curvas de nível, em relação à sua área; o contrário se verifica para as Sub-Bacias $\mathrm{Sb} 5$ e Sb2, em que se observa um relevo mais desenvolvido com maior comprimento das curvas de nível em relação às suas áreas.

A amplitude altimétrica da Bacia do Alto do Rio Meia Ponte variou de 120 a $240 \mathrm{~m}$ (Figura 3B), cujo menor valor foi observado para a Sub-Bacia Sb7, caracterizando-o como relevo suave ondulado. Na Sub-Bacia Sb6 essa amplitude é maior implicando em grande diferencial entre a altitude nas partes altas da bacia e no exutório, aumentando a velocidade média do escoamento na calha do rio, associada à baixa sinuosidade do mesmo, implicando em menor tempo de concentração; com referência à amplitude altimétrica da bacia, espera-se um efeito orográfico maior no processo de formação das chuvas na SubBacia Sb6, seguida das Sb1, Sb3 e Sb4, por apresentarem altitudes máximas variando entre 1000 a $1040 \mathrm{~m}$.

Pelos valores encontrados das relações dos relevos verificase que as Sub-Bacias Sb5 e Sb7, embora tenham menores amplitudes altimétricas com relação às demais, foram as que apresentaram maiores valores da relação do relevo (Rr), devido aos menores comprimentos de seus rios principais, tendo uma resposta mais rápida na propagação de uma cheia no seu exutório. Para a Sub-Bacia Sb5 a Rr acompanhou a tendência da declividade média da bacia, o mesmo não se verificando para a Sb7. 
Analisando os índices de rugosidade (Ir), nota-se que o maior valor foi encontrado para a Sub-Bacia Sb3 e Sb6, implicando em relevo mais colinoso e dissecado, o que pode ser verificado pela maior amplitude altimétrica entre as bacias analisadas e os canais mais entalhados, conferindo baixa densidade de drenagem (Tabela 4). Para as Sub-Bacias Sb1, $\mathrm{Sb} 2, \mathrm{Sb} 4$ e Sb5, que apresentaram valores aproximados de amplitude altimétrica, os índices de rugosidade variaram com a densidade drenagem. Com o aumento da Dd o valor da distância horizontal média entre a linha divisória entre as bacias e os canais adjacentes é reduzido, aumentando a declividade da vertente e diminuindo o percurso médio do escoamento superficial sobre os terrenos dessas sub-bacias. A sub-bacia Sb7, devido à sua menor amplitude altimétrica entre as bacias analisadas e baixa densidade de drenagem, foi a que apresentou o menor índice de rugosidade.

Com base nos parâmetros dimensionais das sub-bacias apresentadas na Tabela 4, calcularam-se os quadrados médios das razões entre os parâmetros lineares $\left(\mathrm{Rm}^{2}\right)$ e as razões das áreas entre duas bacias (A/A') permitindo, assim, a análise de semelhança entre as sub-bacias. Foram realizadas 21 combinações, analisando $\mathrm{Rm}^{2}$ e A/A' para os pares de subbacias, e se verificou, com exceção das Sub-Bacias Sb5 e Sb6, analisadas conjuntamente, para as demais combinações que há semelhança geométrica, o que pode ser visualizado na Figura 4, pela proximidade da linha 1:1.

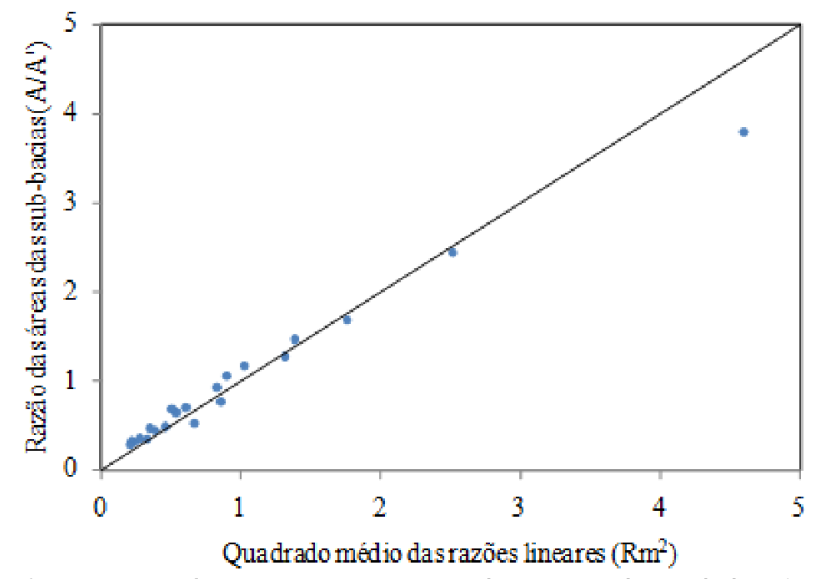

Figura 4. Relação entre a razão das áreas das sub-bacias $\left(A / A^{\prime}\right)$ e o quadrado médio das razões lineares $\left(\mathrm{Rm}^{2}\right)$

\section{CONLUSÕES}

1. As áreas com classes de declividade plana a ondulada associadas aos Latossolos e Argissolos cultivadas com pastagens, agricultura e reflorestamento, predominam na área da Bacia Hidrográfica do Alto Meia Ponte.

2. Nas áreas com relevo de ondulado a escarpado, com predominância dos Argissolos e Cambissolos, verificou-se um padrão de drenagem mais ramificado, principalmente na SubBacia Sb2.

3. As Sub-Bacias Sb2 e Sb7 estão mais propensas aos picos de cheia em resposta a chuvas de grandes intensidades.

4. O formato alongado das Sub-Bacias Sb1, Sb3, Sb4, Sb5 e Sb6 tende a proporcionar um maior tempo de concentração na fase canal devido à menor sinuosidade e extensão do curso d'água principal.

\section{LITERATURA CITADA}

Alcântara, E. H.; Amorim, A. J. Análise morfométrica de uma bacia hidrográfica costeira: Um estudo de caso. Revista Caminhos da Geografia, v.7, p.70-77, 2005.

Alpino, S. O.; Pereira, F. C. S.; Leão, O. M. R. Parâmetros morfométricos do alto curso da bacia do Rio Macaé (RJ): Subsídios ao entendimento da dinâmica geomorfológica. Revista Tamoios, v.4, p.1-23, 2007.

Alves, J. M. P.; Castro, P. T. A. Influência de feições geológicas na morfologia da bacia do Rio Tanque (MG) baseada no estudo de parâmetros morfométricos e análise de padrões de lineamentos. Revista Brasileira de Geociências, v.33, p.117-127, 2003.

Alves Sobrinho, T.; Oliveira, P. T. S.; Rodrigues, D. B. B.; Ayres, F. M. Delimitação automática de bacias hidrográficas utilizando dados SRTM. Engenharia Agrícola, v.30, p.46-57, 2010.

Andrade, L. V. P.; Ferreira, E.; Botelho, S. A.; Davide, A. C. Caracterização física da bacia hidrográfica do ribeirão Santa Cruz, Lavras, MG e uso conflitante da terra em suas áreas de preservação permanente. Revista Cerne, v.11, p.49-60, 2005.

Andrade, N. L. R.; Xavier, F. V.; Alves, E. C. R. F.; Silveira A.; Oliveira, C. U. R. Caracterização morfométrica e pluviomética da Bacia do Rio Manso, MT. Revista Geociências, v.27, p.237-248, 2008.

Antoneli, V; Thomaz, E. L. Caracterização do meio físico da bacia do Arroio Boa Vista, Guamiranga-PR. Revista Caminhos da Geografia, v.8, p.46-58, 2007.

Barbosa, M. E. F.; Furrier, M. Análise morfométrica da bacia hidrográfica do Rio Guruji, litoral sul do estado da Paraíba. In: Simpósio Brasileiro de Geografia Física Aplicada,13, 2009, Viçosa. Anais...Viçosa: UFV, 2009. CD-Rom

Calil, P. M. potencial de uso por atributos morfométricos dos solos da bacia hidrográfica do alto Meia Ponte, Goiás. Goiânia: UFG, 2009. 113p. Dissertação Mestrado

Cardoso, C. A.; Dias, H. C. T.; Soares, C. P. B; Sebastião Venâncio Martins, S. V. Caracterização morfométrica da bacia hidrográfica do Rio Debossan, Nova Friburgo, RJ. Revista Árvore, v.30, p.241-248, 2006.

Demattê, J. A. M.; Demétrio, V. A. Fotointerpretação de padrões de drenagem em amostras circulares na caracterização de solos basálticos do estado do Paraná. Revista Brasileira de Ciência do Solo, v.20, p.109-115, 1996.

EMBRAPA - Empresa Brasileira de Pesaquisa Agropecuária. Sistema Brasileiro de Classificação de Solos. Embrapa Produção de Informação. Rio de Janeiro: Embrapa Solos, 2006.367p.

Feltran Filho, A.; Lima, E. F. Considerações morfométricas da bacia do Rio Uberabinha - Minas Gerais. Sociedade \& Natureza, v.19, p.65-80, 2007.

França, G. V. Interpretação fotográfica de bacias e de redes de drenagem aplicada solos da região de Piracicaba. Piracicaba: USP, 1968. 151p. Tese Doutorado 
Gobbi, A. F.; Torres, J. L. R.; Fabian, A. J. Diagnóstico ambiental da microbacia do córrego do Melo em Uberaba- MG. Revista Caminhos de Geografia, v.9, p.206-223, 2008.

Lima, W. P.; Zakia, M. J. B. Hidrologia de matas ciliares. In: Rodrigues, R. R.; Leitão Filho, H. F. Matas ciliares: Conservação e recuperação. São Paulo: EDUSP, 2000. p.33-44.

Lucas, A. A. T.; Folegatti, M. V.; Duarte, S. N. Qualidade da água em uma microbacia hidrográfica do Rio Piracicaba, SP. Revista Brasileira de Engenharia Agrícola e Ambiental, v.14, p.937-943, 2010.

Machado, C. J. S. Recursos hídricos e cidadania no Brasil: limites, alternativas e desafio. Ambiente \& Sociedade, v.6, p.121-136, 2003.

Oliveira, P. T. S.; Alves Sobrinho, T.; Steffen, J. L.; Rodrigues, D. B. B. Caracterização morfométrica de bacias hidrográficas através de dados SRTM. Revista Brasileira de Engenharia Agrícola e Ambiental, v.14, p.819-825, 2010.

Périco, E.; Cemin, G.; Arend, U.; Rempel, C.; Eckhardt, R. R. Análise fisiográfica da bacia hidrográfica do rio Forqueta, RS. In: Simpósio Brasileiro de Sensoriamento Remoto, 15, 2011, Curitiba, Anais... São José dos Campos: INPE, 2011. p.1200-1207.

Pissarra, T. C. T.; Politano, W.; Ferraudo, A. S. Avaliação de características morfométricas na relação solo-superfície da bacia hidrográfica do Córrego Rico, Jaboticabal (SP). Revista Brasileira de Ciência do Solo, v.28, p.297-305, 2004.

Politano, W.; Pissarra, T.C.T. Relações entre características morfométricas quantitativas e estimativas da vazão em função da área em microbacias hidrográficas de $2^{\mathrm{a}}$ ordem de magnitude. Revista de Engenharia Agrícola, v.23, p.179-186, 2003.

Porto, M. F. A.; Porto, R. L. L. Gestão de bacias hidrográficas. Estudos Avançados, v.22, p.43-60, 2008.

Rabelo, C. G.; Ferreira, M. E.; Araújo, J. V. G.; Stone, L. F.; Silva, S. C.; Gomes, M. P. Influência do uso do solo na qualidade da água no bioma Cerrado: um estudo comparativo entre bacias hidrográficas no estado de Goiás, Brasil. Revista Ambiente \& Água: Na interdisciplinary. Journal of Applied Science, v.4, p.172-187, 2009.

Santos, E. H. M.; Griebeler, N. P.; Oliveira, L. F. C. Relação entre uso do solo e comportamento hidrológico na Bacia Hidrográfica do Ribeirão João Leite. Revista Brasileira de Engenharia Agrícola e Ambiental, v.14, p.826-834, 2010.

Santos, G. V.; Dias, H. C. T.; Silva, A. P. S.; Maced, M. N. C. Análise hidrológica e socioambiental da bacia hidrográfica do córrego Romão dos Reis, Viçosa-MG. Revista Árvore, v.31, p.931-940, 2007.
Silva, F. B.; Carvalho, W. A. Discriminação de solos por interpretação fotográfica da rede de drenagem. Holos Environment, v.2, p.65-86, 2002.

Souza, E. R.; Fernandes, M. R. Sub-bacias hidrográficas: Unidades básicas para o planejamento e a gestão sustentáveis das atividades rurais. Informe Agropecuário, v.21, p.15-20, 2000.

Sucupira, P. A. P.; Pinheiro, L. S.; Rosa, M. F. Caracterização morfométrica do médio e baixo curso do Rio Acaraú, Ceará, Brasil. In: Simpósio Nacional de Geomorfologia, 6, 2006. Anais...Goiânia: UFG, 2006. CD-Rom

Teodoro, V. L. I.; Teixeira, D.; Costa, D. J. L.; Fuller, B. B. O conceito de bacia hidrográfica e a importância da caracterização morfométrica para o entendimento da dinâmica ambiental local. Revista Uniara, v.20, p.137-157, 2007.

Tonello, K. C.; Dias, H. C. T.; Souza, A. L.; Ribeiro, C. A. A. S.; Leite, F. P. Morfometria da bacia hidrográfica da Cachoeira das Pombas, Guanhães-MG. Revista Árvore, v.30, p.849-857, 2006.

Torres, J. L. R.; Fabian, A. J.; Silva, A. L.; Pessoa, E. J.; Silva, E. C.; Resende, E. F. Diagnostico ambiental e análise morfométrica da microbacia do córrego Lanhoso em Uberaba, MG. Revista Caminhos de Geografia, v.9, p.1-11, 2008.

Torres, J. L. R.; Guidolini, J. F.; Santana, M. G.; Santos, E. C.; Laureano, M. B. J. Avaliação das características morfológicas e hidrológicas da microbacia do córrego Buracão, afluente do Rio Uberaba. Revista Caminhos de Geografia, v.11, p.157-167, 2010.

Vanacker, V.; Molina, A.; Govers, G.; Poesen, J.; Dercon, G.; Deckers, S. River channel response to short-term humaninduced change in landscape connectivity in Andean ecosystems. Geomorphology, v.72, p.340-353, 2005.

Valle Júnior, R. F; Pissarra, T. C. T.; Passos, A. O.; Ramos, T. G.; Abdala, Vera L. Diagnóstico das áreas de preservação permanente na bacia hidrográfica do rio Tijuco, ItuiutabaMG, utilizando tecnologia SIG. Engenharia Agrícola, v.30, p.495-503, 2010.

Zanetti, S. S.; Silva, J. M. A.; Sousa, E. F.; Oliveira, V. P. S.; Almeida, F. T. Modelagem hidrológica em microbacia hidrográfica Parte I: Aprimoramento do modelo HidroBacia. Revista Brasileira de Engenharia Agrícola e Ambiental, v.13, p.429-434, 2009. 